\title{
Evaluation of Drogue Parachute Damping Effects Utilizing the Apollo Legacy Parachute Model
}

\author{
Kelly M. Currin ${ }^{1}$ \\ NASA Kennedy Space Center, FL, 32899 \\ Joe D. Gamble ${ }^{2}$ \\ Lockheed Martin Space Systems/MEIT, Houston, TX, 77058 \\ Daniel A. Matz ${ }^{3}$ \\ NASA Johnson Space Center, Houston, TX, 77058 \\ David R. Bretz ${ }^{4}$ \\ Barrios Technology/NASA Johnson Space Center, Houston, TX, 77058
}

\begin{abstract}
Drogue parachute damping is required to dampen the Orion Multi Purpose Crew Vehicle (MPCV) crew module (CM) oscillations prior to deployment of the main parachutes. During the Apollo program, drogue parachute damping was modeled on the premise that the drogue parachute force vector aligns with the resultant velocity of the parachute attach point on the $\mathbf{C M}$. Equivalent $\mathbf{C m}_{\mathrm{q}}$ and $\mathbf{C m}_{\alpha}$ equations for drogue parachute damping resulting from the Apollo legacy parachute damping model premise have recently been developed. The MPCV computer simulations ANTARES and Osiris have implemented high fidelity twobody parachute damping models. However, high-fidelity model-based damping motion predictions do not match the damping observed during wind tunnel and fullscale free-flight oscillatory motion. This paper will present the methodology for comparing and contrasting the Apollo legacy parachute damping model with fullscale free-flight oscillatory motion. The analysis shows an agreement between the Apollo legacy parachute damping model and full-scale free-flight oscillatory motion.
\end{abstract}

\footnotetext{
${ }^{1}$ Aerospace Technologist, Fluids Division, NE-F4.

${ }^{2}$ Senior Engineer, Orion Aerosciences/GN\&C, 2625 Bay Area Blvd/A7C, AIAA Associate Fellow.

${ }^{3}$ Insert Job Title, Department Name, Address/Mail Stop, and AIAA Member Grade for third author.

${ }^{4}$ Senior Scientist, Image Science \& Analysis Group/JSC-KX, 2101 NASA Rd. 1/Code: KX.
} 


\section{Nomenclature}

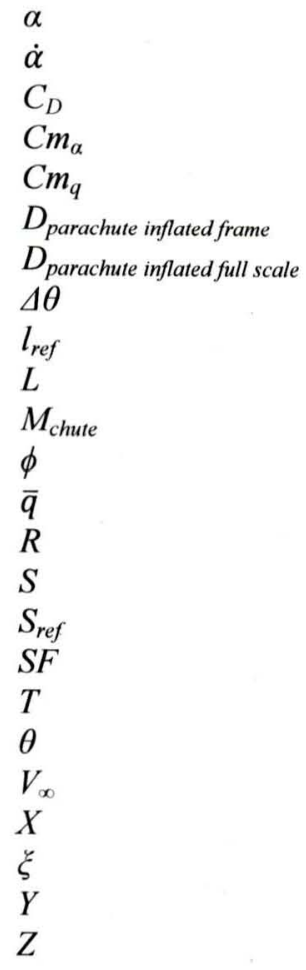

$=$ angle of attack

$=$ rate of change of angle of attack

$=$ drag force coefficient

$=$ pitching moment coefficient

$=$ pitching moment damping coefficient

$=$ diameter of parachute inflated in frame

$=$ diameter of parachute inflated full scale

$=$ angle between parachute trim position and dynamic rotated position

$=$ reference length

$=$ lift

$=$ moment of parachute

$=$ pitch angle

$=$ dynamic pressure

$=$ riser line length

$=$ area

reference area

scaling factor

resultant distance vector magnitude

roll angle

freestream velocity

vertical distance from center of parachute to center of grid

yaw angle

= lateral distance from center of parachute to center of grid

$=$ longitudinal distance from center of parachute to center of grid

\section{Introduction}

\section{A. Concept Overview}

Drogue parachutes are designed to be deployed from rapid-moving objects to reduce the speed of the object and provide a stable platform for the deployment of the main parachutes. The Orion CM employs drogue parachutes which contribute to the system damping to reduce the CM oscillatory motion between drogue opening and drogue release. System damping includes both the CM damping and drogue damping contributions, and the sum of their contributions creates stable damping to reduce the amplitude of the CM oscillatory motion.

The purpose of the analysis presented in this paper is to investigate the effect of drogue parachutes on Orion $\mathrm{CM}$ dynamics. The Apollo legacy parachute damping model is recalled, improved, documented, and re-justified through comparisons with the drogue parachute motion from the Pad Abort 1 (PA-1) free-flight test.

Bass Redd, retired engineer, Johnson Space Center, is credited with developing the original legacy parachute damping concept. During the Apollo parachute testing era, drogue parachute damping was modeled on the premise that the drogue parachute force vector aligns with the resultant velocity of the parachute attach point on the CM. This methodology applies to similar parachute configurations such as the MPCV design.

\section{B. Model Overview}

The Apollo legacy parachute model (also referred to as the low-fidelity parachute model) simulates the effect of a parachute system on a 6-degree-of-freedom body by applying the assumption that the parachute force vector is aligned opposite the velocity of the attach point. This velocity is calculated as the sum of the velocity of the center of mass of the vehicle and a component from the vehicle's rotational velocity. It is this rotational component that causes a hysteresis in the moment arm of the parachute force, and thus creates a damping effect on the vehicle. 
The high-fidelity parachute model is a multi-body simulation, with the vehicle and each parachute in the cluster modeled as separate 6-degree-of-freedom bodies. An elastic riser connects each parachute to the vehicle and couples the dynamics. This multi-body approach allows the high-fidelity parachute model to capture dynamics that the Apollo legacy model cannot, such as the pendulum motion of the vehicle under the parachute cluster. It also allows the high-fidelity parachute to simulate parachute deployment to higher fidelity. Another result of the multibody approach is that there is no distinct damping model. The damping behavior should instead be captured implicitly through the elastic coupling.

The MPCV computer simulations ANTARES and Osiris have implemented high fidelity two- body parachute damping models. However, high-fidelity model-based damping motion predictions do not match the damping observed during wind tunnel and full-scale free-flight oscillatory motion. The analysis presented in this paper shows an agreement between the Apollo legacy parachute damping model and full-scale free-flight oscillatory motion. It is concluded that the Apollo legacy parachute damping model provides a better simulation of the free-flight motion than the two-body model for low mass drogue parachutes.

\section{Derivation of Apollo Legacy Damping Model}

The Apollo legacy parachute damping model is based on the premise that the drogue parachute force vector aligns with the resultant velocity of the parachute attach point on the CM.

During the Apollo program the drogue parachute damping was attributed to a hysteresis in dynamic pressure on the parachute as the velocity on the parachute varied due to the resultant velocity of the attach point on the CM. Recent analysis of the drogue damping on the Orion program has shown that the drogue damping is actually due to a hysteresis in the moment arm of the parachute force as the parachute aligns with the resultant velocity of the attach point. The recent analysis allowed derivation of equations for the equivalent frequency and damping effects of the drogue parachute on the CM. The following analysis provides a summary of the derivation of the frequency and damping equations. ${ }^{1}$

Figure 1 shows a single drogue parachute at the alpha trim position and at a location corresponding to a $\mathrm{CM}$ angle of attack displaced from trim. 


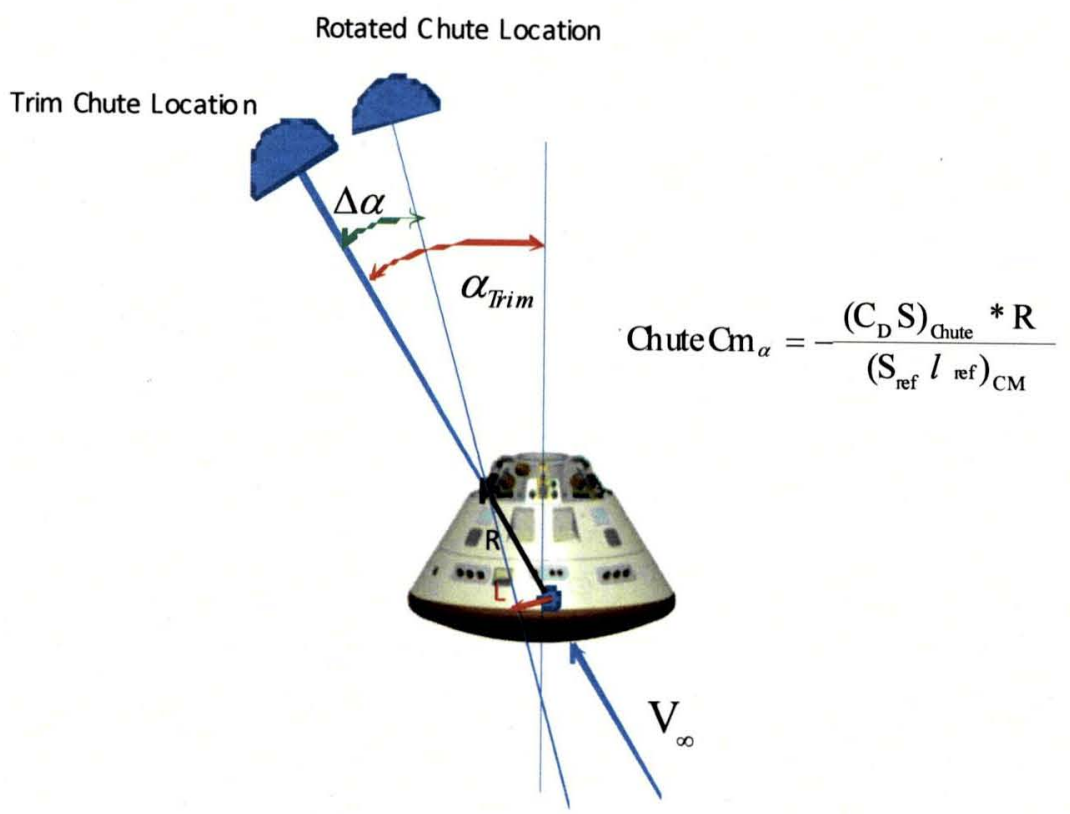

Figure 1. Single Drogue Parachute Displacement From Alpha Trim.

The following equations show the equivalence of the drogue parachute moment due to excursions in alpha from trim to the moment from a linear $\mathrm{Cm}_{\alpha}$ on the $\mathrm{CM}$.

$$
\mathrm{M}_{\text {Chute }}=-\left(\mathrm{C}_{\mathrm{D}} \mathrm{S}\right)_{\text {Chute }} * \overline{\mathrm{q}} * \mathrm{~L}=-\left(\mathrm{C}_{\mathrm{D}} \mathrm{S}\right)_{\text {Chute }} * \overline{\mathrm{q}} * \mathrm{R} * \sin \Delta \alpha
$$

For small $\Delta \alpha, \sin \Delta \alpha \approx \Delta \alpha$ (good approximation for $\Delta \alpha \leq 30^{\circ}$ ). Equate chute moment from $\Delta \alpha$ to $\mathrm{Cm}_{\alpha}$ moment on CM.

$$
\begin{gathered}
\mathrm{Cm}_{\alpha} * \Delta \alpha * \overline{\mathrm{q}} *\left(\mathrm{~S}_{\text {ref }} * \mathrm{l}_{\text {ref }}\right)_{\mathrm{CM}}=-\left(\mathrm{C}_{\mathrm{D}} \mathrm{S}\right)_{\text {Chute }} * \overline{\mathrm{q}} * \mathrm{R} * \Delta \alpha \\
\text { Equivalent Chute } \mathrm{Cm}_{\alpha}=-\frac{\left(\mathrm{C}_{\mathrm{D}} \mathrm{S}\right)_{\text {Chute }} * \overline{\mathrm{q}} * \mathrm{R} * \Delta \alpha}{\Delta \alpha * \overline{\mathrm{q}} *\left(\mathrm{~S}_{\text {ref }} * \mathrm{l}_{\text {ref }}\right)_{\mathrm{CM}}} \\
\text { Chute } \mathrm{Cm}_{\alpha}=-\frac{\left(\mathrm{C}_{\mathrm{D}} \mathrm{S}\right)_{\text {Chute }} * \mathrm{R}}{\left(\mathrm{S}_{\text {ref }} * \mathrm{l}_{\text {ref }}\right)_{\mathrm{CM}}}
\end{gathered}
$$

If the wake behind the $\mathrm{CM}$ results in a reduction in the dynamic pressure acting on the drogue parachute, an approximation for the effect on the parachute $\mathrm{Cm}_{\alpha}$ can be obtained by multiplying by the ratio of the wake dynamic pressure to the free stream dynamic pressure.

The equivalent $\mathrm{Cm}_{\alpha}$ from the drogue parachute is therefore dependent on the $\mathrm{C}_{\mathrm{D}} \mathrm{S}$ of the parachute and the distance from the center of gravity (CG) to the parachute attach point.

A similar approach is used to derive the equivalent $\mathrm{Cm}_{\mathrm{q}}$ based on Figure 2. 


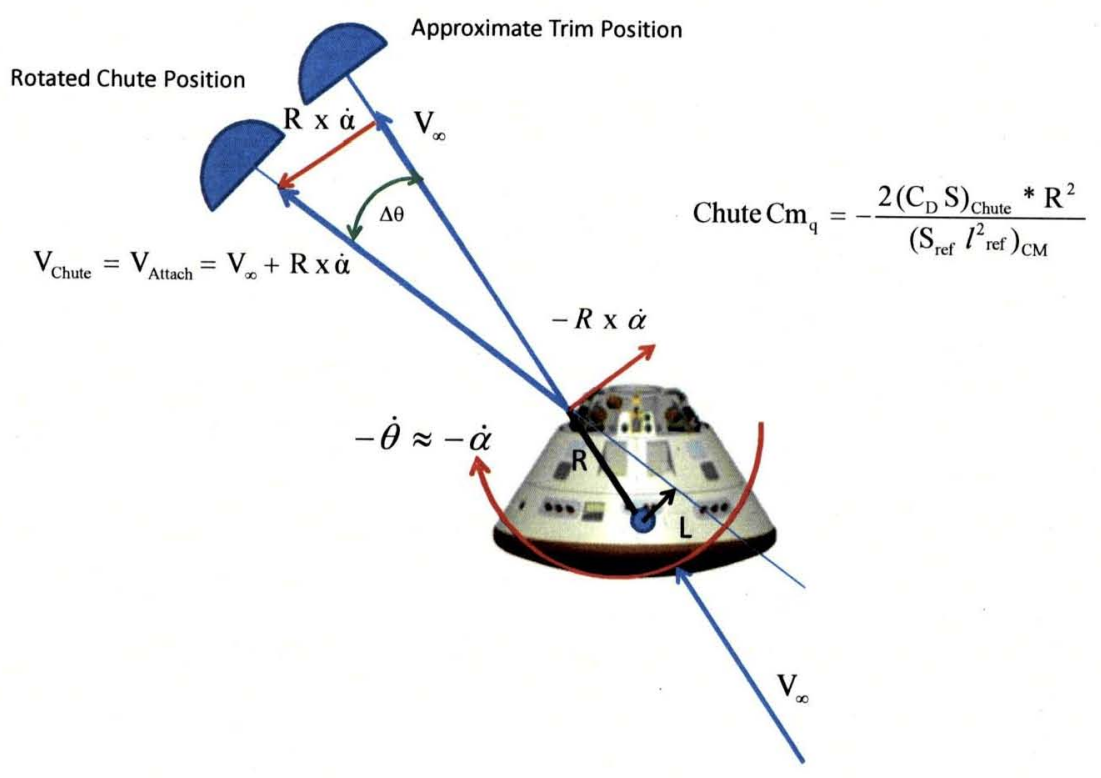

Figure 2. Representation of the Drogue Attach Point on the CM.

$$
\tan \Delta \theta=\frac{-\mathrm{R} * \dot{\alpha}}{\mathrm{V}_{\infty}}
$$

For small $\Delta \theta, \tan \Delta \theta \approx \Delta \theta\left(\right.$ good approximation for $\left.\Delta \theta \leq 30^{\circ}\right)$.

$$
\begin{gathered}
\mathrm{L}=\mathrm{R} * \sin \Delta \theta \approx \mathrm{R} * \tan \Delta \theta \\
\mathrm{M}_{\text {Chute }}=\left(\mathrm{C}_{\mathrm{D}} \mathrm{S}\right)_{\text {Chute }} * \overline{\mathrm{q}}_{\text {Chute }} * \mathrm{~L}=\left(\mathrm{C}_{\mathrm{D}} \mathrm{S}\right)_{\text {Chute }} * \overline{\mathrm{q}}_{\text {Chute }} * \mathrm{R} * \sin \Delta \theta \\
\mathrm{M}_{\text {Chute }}=-\left(\mathrm{C}_{\mathrm{D}} \mathrm{S}\right)_{\text {Chute }} * \overline{\mathrm{q}}_{\text {Chute }} * \frac{\mathrm{R}^{2} * \dot{\alpha}}{\mathrm{V}_{\infty}}
\end{gathered}
$$

Equate chute moment from $\dot{\alpha}$ to $\mathrm{Cm}_{\mathrm{q}}$ moment on $\mathrm{CM}$.

$$
\begin{gathered}
\mathrm{Cm}_{\mathrm{q}} * \frac{\dot{\alpha} \mathrm{l}_{\text {ref }}}{2 \mathrm{~V}_{\infty}} *\left(\overline{\mathrm{q}} * \mathrm{~S}_{\text {ref }} * \mathrm{l}_{\text {ref }}\right)_{\mathrm{CM}}=-\left(\mathrm{C}_{\mathrm{D}} \mathrm{S}\right)_{\text {Chute }} * \overline{\mathrm{q}}_{\text {Chute }} * \frac{\mathrm{R}^{2} * \dot{\alpha}}{\mathrm{V}_{\infty}} \\
\text { Equivalent Chute } \mathrm{Cm}_{\mathrm{q}}=-\frac{\left(\mathrm{C}_{\mathrm{D}} \mathrm{S}\right)_{\text {Chute }} * \overline{\mathrm{q}}_{\text {Chute }} * \frac{\mathrm{R}^{2} * \dot{\alpha}}{\mathrm{V}_{\infty}}}{\frac{\dot{\alpha} \mathrm{l}_{\text {ref }} *\left(\overline{\mathrm{q}} * \mathrm{~S}_{\text {ref }} * \mathrm{l}_{\text {ref }}\right)_{\mathrm{CM}}}{2 \mathrm{~V}_{\infty}}} \\
\text { Chute } \mathrm{Cm}_{\mathrm{q}}=-\frac{2 *\left(\mathrm{C}_{\mathrm{D}} \mathrm{S}\right)_{\text {Chute }} * \overline{\mathrm{q}}_{\text {Chute }} * \mathrm{R}^{2}}{\left(\overline{\mathrm{q}} * \mathrm{~S}_{\text {ref }} * \mathrm{l}_{\text {ref }}^{2}\right)_{\mathrm{CM}}}
\end{gathered}
$$

Note $\overline{\mathrm{q}}_{\text {chute }}$ is approximately $\overline{\mathrm{q}}_{\text {СM }}$. Reductions in $\overline{\mathrm{q}}_{\text {chute }}$ due to wake effects can be accommodated by multiplying by the ratio to $\overline{\mathrm{q}}_{\mathrm{CM}}$.

$$
\text { Chute } \mathrm{Cm}_{\mathrm{q}}=-\frac{2 *\left(\mathrm{C}_{\mathrm{D}} \mathrm{S}\right)_{\text {Chute }} * \mathrm{R}^{2}}{\left(\mathrm{~S}_{\mathrm{ref}} * \mathrm{l}_{\mathrm{ref}}^{2}\right)_{\mathrm{CM}}}
$$


The equivalent $\mathrm{Cm}_{\mathrm{q}}$ from the drogue parachute is proportional to the CDS of the parachute and to the square of the distance from the CG to the parachute attach point.

These equations provide a simple method of calculating the equivalent frequency and damping and should be a valuable resource for preliminary design of drogue parachute damping systems. The equations were validated by modifying the GEMASS 6-degree-of-freedom simulation to replace the Apollo legacy chute model with equivalent $\mathrm{Cm}_{\mathrm{q}}$ and $\mathrm{Cm}_{\alpha}$ values computed from the equations. The simulation results were almost identical for the two simulation runs using the chute model and using the equations.

It is important to note that the key assumption that the parachute aligns with the resultant velocity of the attach point is only valid for small parachutes (i.e. drogue parachutes) with small mass. For larger parachutes (i.e. main parachutes), the parachute and enclosed air mass are too large to rapidly change with the attach point motion.

\section{Summary of Analysis}

\section{A. Orion PA-1 Free-Flight Test Analysis}

In November 2010, the NESC was requested to investigate the effect of drogue parachutes on Orion CM dynamics resulting from a lack of agreement between the Orion Pad Abort 1 (PA-1) CM damping motion and the simulated damping motion. ${ }^{2}$ The NESC enlisted the support of several Apollo parachute experts, Rick Barton, Bass Redd and Joe Gamble, to perform this analysis.

The PA-1 full-scale free-flight test was conducted on 6 May 2010 at White Sands Test Facility (WSTF). One of the primary objectives of the test was to demonstrate the parachute recovery system sequencing and performance. The test configuration included a development launch abort system (LAS) and a CM consisting of a boiler plate outer mold line (OML) structure with forward bay and cover, firstgeneration parachutes and flight representative mass properties. The parachute system was comprised of two drogue parachutes ( $23 \mathrm{ft}$ diameter each) deployed at $\mathrm{T}+25$ seconds and three main parachutes $(116 \mathrm{ft}$ diameter each) deployed at $\mathrm{T}+31$ seconds. The PA-1 trajectory is shown in Figure $3 .^{3}$

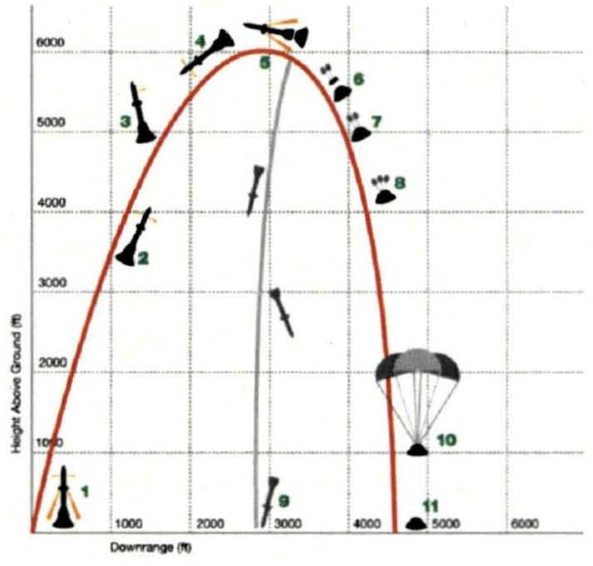

Figure 3. PA-1 Trajectory.

The PA-1 test flight CM-mounted camera recorded $16 \mathrm{~mm}$ film with an associated timestamp for each frame. The camera was a LOCAM III $16 \mathrm{~mm}$ film camera with a wide lens. The film was digitally converted to an HD format (1920x1080) quicktime movie by Photochem of Burbank, CA. Data from the PA-1 test flight was recorded as a function of the best estimated trajectory (BET) timestamp. The following methodology was used to sync the film timestamp with the BET timestamp:

1. Make a best estimate from the PA-1 film frame timestamp at which the CM drogues are released (39:29.865) and match that time with the BET timestamp for the commanded CM drogue release (13:00:24.763)

2. Time-step each film frame timestamp and BET timestamp by 0.01 seconds for the duration of drogue deployment (5.365 seconds)

3. Match the BET data to the BET timestamp for the period of drogue deployment.

It was appropriate to delay the timeframe of analysis until the drogue parachutes were in the view of the CMmounted camera (film frame timestamp 39:31.355, corresponding to a BET timestamp of 13:00:26.493). The drogues were in view for a total time of 3.740 seconds, but were only in stable view for 3.500 seconds. Thus, 3.500 seconds was chosen as the period of review for the PA-1 flight test drogue motion, starting at BET $=13: 00: 26.493$ 
seconds** and ending at BET $=13: 00: 29.993$ seconds. The frame rate of the camera mounted on the CM was 200 frames per second, resulting in a total of 700 frames available for analysis.

In order to develop comparisons between the three analysis methods, it was necessary to determine the proper variables to be analyzed. The GEMASS simulation computes the pitch, $\varphi$, and yaw, $\xi$, angles generated by the motion of the drogue parachutes in time. These angles are the basis of the comparison between the three analysis methods and will be computed in both the manual analysis method and the tracking program method for comparison with the GEMASS simulation. Three dimensions are required to determine the pitch and yaw angles: $\mathrm{X}, \mathrm{Y}$ and $\mathrm{Z}$, relative to a fixed point on the image screenshot. The manual analysis method has two of the three dimensions known ( $\mathrm{Y}$ and $\mathrm{Z}$ ), but $\mathrm{X}$ must be calculated in order to compute the pitch and yaw angles. The tracking program analysis method has all three of the dimensions available for computing the pitch and yaw angles. Each of the three analysis types and the methodology for determining the pitch and yaw angles for comparison will be described in the following subsections.

\section{Manual Analysis Method}

In order to simplify the manual analysis method, several assumptions were made. First, the distance between the camera attach point and the drogue attach point on the CM was assumed to be much smaller than the total distance between the drogue attach point on the CM and the central point on the parachute. Second, it was assumed that the camera attach point on the $\mathrm{CM}$ is at the same $\mathrm{X}$ and $\mathrm{Z}$ location as the drogue attach point on the $\mathrm{CM}$ and varies only by a Y dimension. Third, the manual measurements of the drogue location in time were taken at the estimated central point location of the deployed drogue parachute vent, and the initial measurement was taken only when the drogue parachutes were both fully deployed and stabilized.

The manual method for estimating the motion during drogue deployment was a straightforward process of capturing image screenshots and measuring drogue central point locations to a fixed location in the image. Due to the high number of frames available for review, only $10 \%$ of the frames (every $10^{\text {th }}$ frame) were manually analyzed. The media available for review was in video format, therefore after determining the frame number corresponding to the desired time interval, the video was paused at the specified frame number and an image screenshot was captured as shown in Figure 4.

A standard measurement grid was superimposed on each image screenshot and the central point of each parachute was estimated and marked on the image. The lateral $(\mathrm{Y}, \mathrm{d})$ and vertical $(\mathrm{Z}, \mathrm{l})$ distance from the central point of the parachute to the center of the standard measurement grid was measured for each parachute as shown in Figure 5.

This process was repeated until the measurements for 70 total frames were recorded.

\footnotetext{
${ }^{* *}$ For the manual analysis. GEMASS analysis began at BET $=13: 00: 26.510$ seconds.
} 


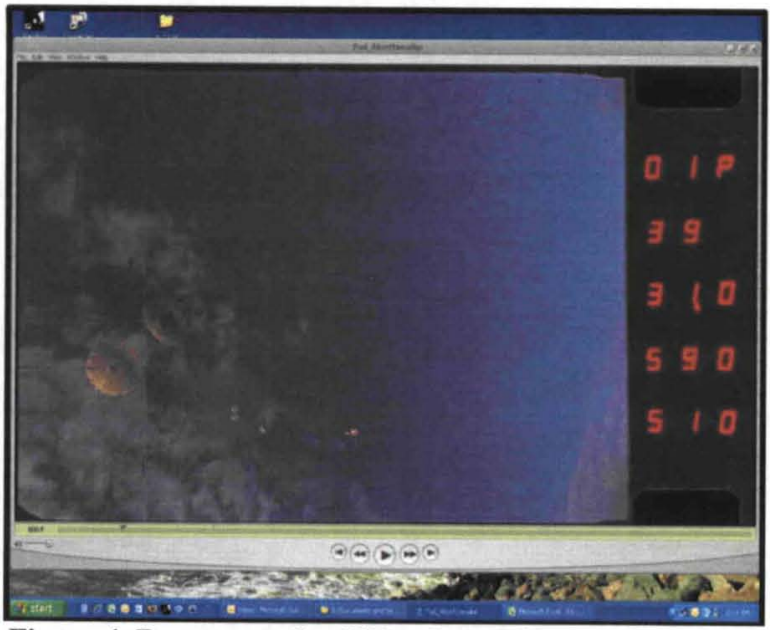

Figure 4. Representative Video Image Screen Snapshot.

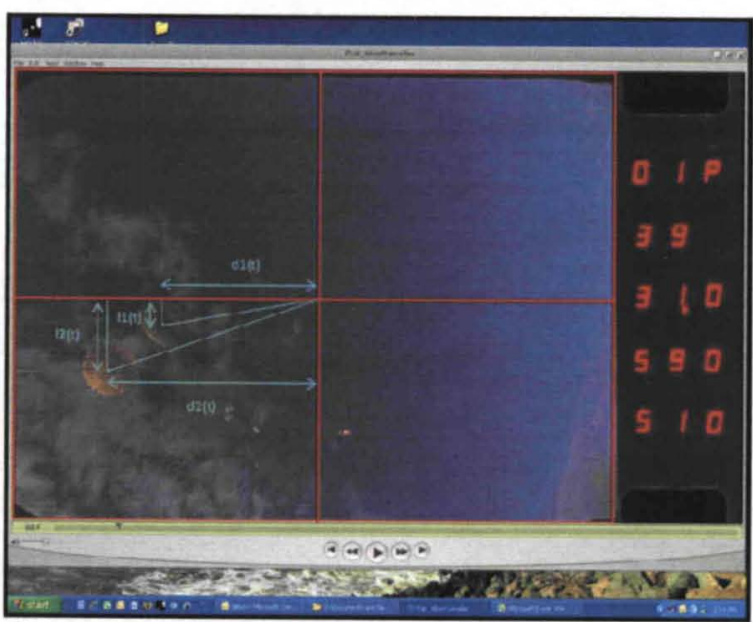

Figure 5. Standard Measurement Grid on Video Image Snapshot. 
In order to simplify the analysis process, the two parachute $\mathrm{Y}$ and $\mathrm{Z}$ dimensions were averaged to obtain one "effective parachute" $Y$ and $Z$ dimension for each image screenshot. Using $R$ for the riser line length, the following equations were used to calculate the resultant distance vector magnitude, $\mathrm{T}$; the roll angle, $\theta$; the $\mathrm{X}$ component of the $\mathrm{S}$ vector; scaling factor, SF; pitch angle, $\phi$; and yaw angle, $\xi$ :

$$
\begin{gathered}
\mathrm{T}=\sqrt{\mathrm{Z}^{2}+\mathrm{Y}^{2}} \\
\theta=\operatorname{ARCSIN}\left(\frac{\mathrm{T}}{\mathrm{R}}\right) \\
\mathrm{X}=\mathrm{R} \cos \theta \\
\mathrm{SF}=\frac{\mathrm{D}_{\text {parachute inflated full scale }}}{\mathrm{D}_{\text {parachute inflated frame }}} \\
\phi=\text { ARCTAN }\left(\frac{\mathrm{Z}}{\mathrm{X}}\right) \\
\xi=\operatorname{ARCTAN}\left(\frac{\mathrm{Y}}{\mathrm{X}}\right)
\end{gathered}
$$

\section{GEMASS Simulation Analysis Method}

The General Electric Missiles and Satellite Systems (GEMASS) computer simulation was the six-degree-of-freedom (6-DOF) simulation used for most of the NASA simulations during the Apollo program. The program has been ported to a PC and is still in limited use for dynamics analyses. The PA-1 vehicle properties and trajectory parameters from the best estimated trajectory (BET) were used to initialize the simulation shortly after drogue parachute deployment. Approximately four seconds of flight were simulated, providing almost two cycles of CM oscillations prior to the drogue parachute release.

The GEMASS simulation computes the pitch, $\varphi$, and yaw, $\xi$, angles generated by the motion of the drogue parachutes in time.

\section{Tracking Program Analysis Method}

The two drogue parachutes were tracked using version 5.2 of the commercially available Trackeye program using a $1920 \times 1080$ quicktime movie digitization of the $16 \mathrm{~mm}$ film. A conversion from the timing on the film to the Best Estimated Trajectory $(\mathrm{BET})$ was given as BET $=$ Film Time $+11: 20: 54.890$. Drogue 1 tracking was started at BET 13:00:25.660 and ended 4.8 seconds later at 13:00:30.465. Drogue 2 tracking was started at 13:00:26.150 and ended 4.1 seconds later at 13:00:30.245. A correlation tracking method was used and no frames were skipped during the tracking.

With the help of Rod Bogue of Dryden Flight Research Center, information about the camera and lens were obtained from Gil Pendley, president of Visual Instruments in Lancaster, CA who was involved in the acquisition and installation of the camera. The lens on the camera was a $5.9 \mathrm{~mm} \mathrm{f} / 1.8 \mathrm{R} 7$ type by Angenieux. Using known dimensions for the $16 \mathrm{~mm}$ film and sprocket holes, the focal length was converted to 841.9 pixels for the digital movie copy and the principal point was determined to be at 830 pixels from the left side and 540 pixels from the top. Documentation for the lens provided a radial distortion curve. Following the Brown/Bouguet lens distortion model, a polynomial was fit to the curve to get the appropriate parameters to compensate for the moderate amount of barrel distortion of this lens which increases to about 38 pixels $(0.27 \mathrm{~mm})$ near the edges of the frame. These parameters were entered into the Trackeye software, and the distortion was removed from the tracking data.

Motion of the drogues on the image in pixels relative to the principal point were converted to pitch and yaw angles by using the known focal length in pixels as the distance out of the image plane from the principal point to the perspective center. As was stated earlier, the distance between the camera position and the drogue attach point was small relative to the distance between the camera and the drogues, so the angles measured at the camera can be 
considered equivalent to the angles that would be observed at the attach point for the drogues. The motion of the drogues relative to the principal point and perspective center is shown in Figure $\mathrm{X}$.

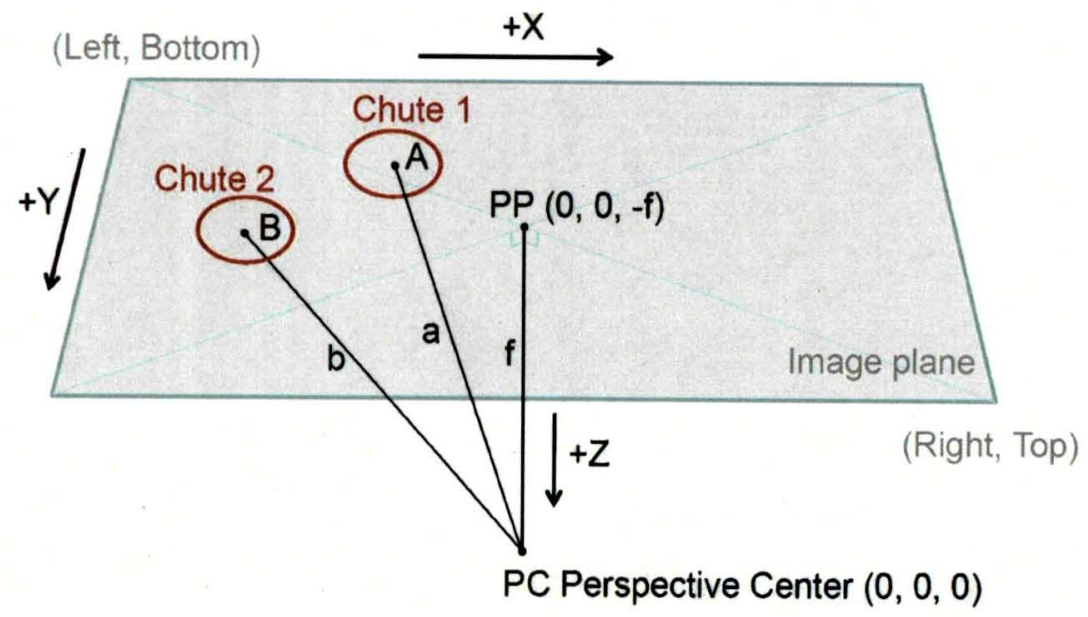

Figure 6: Motion of Drogues Using Trackeye Software.

\section{B. 109-CD Vertical Spin Tunnel Analysis}

Results from the LaRC Vertical Spin Tunnel Test 109-CD were also compared with GEMASS simulation results using the Apollo drogue damping model. Wind tunnel data with 1- and 2- drogue parachutes were obtained. ${ }^{4}$ The wind tunnel data was scaled to full-scale values which were used for the comparison with the GEMASS results. $\mathrm{C}_{\mathrm{A}}$ and $\mathrm{C}_{\mathrm{N}}$ simulation values for the $\mathrm{CM}$ were based on wind tunnel data from test $82-\mathrm{CD}$ and the $\mathrm{Cm}$ and $\mathrm{Cm}_{q}$ values were based on test $117-\mathrm{CD}$. Slight adjustments to the drogue parachute attach point were required to obtain the trim angle of attack observed in the test.

\section{Results of Analysis}

\section{A. Orion PA-1 Free-Flight Test Analysis}

The results for the pitch and yaw angles using the three analysis methods for the 700 frames when the drogues were in view are presented in tabular form in Appendix A. The minimum and maximum values for each analysis method are highlighted in yellow and green, respectively, for the pitch and yaw angles. Figure 7 illustrates the comparison between the three analysis methods. 


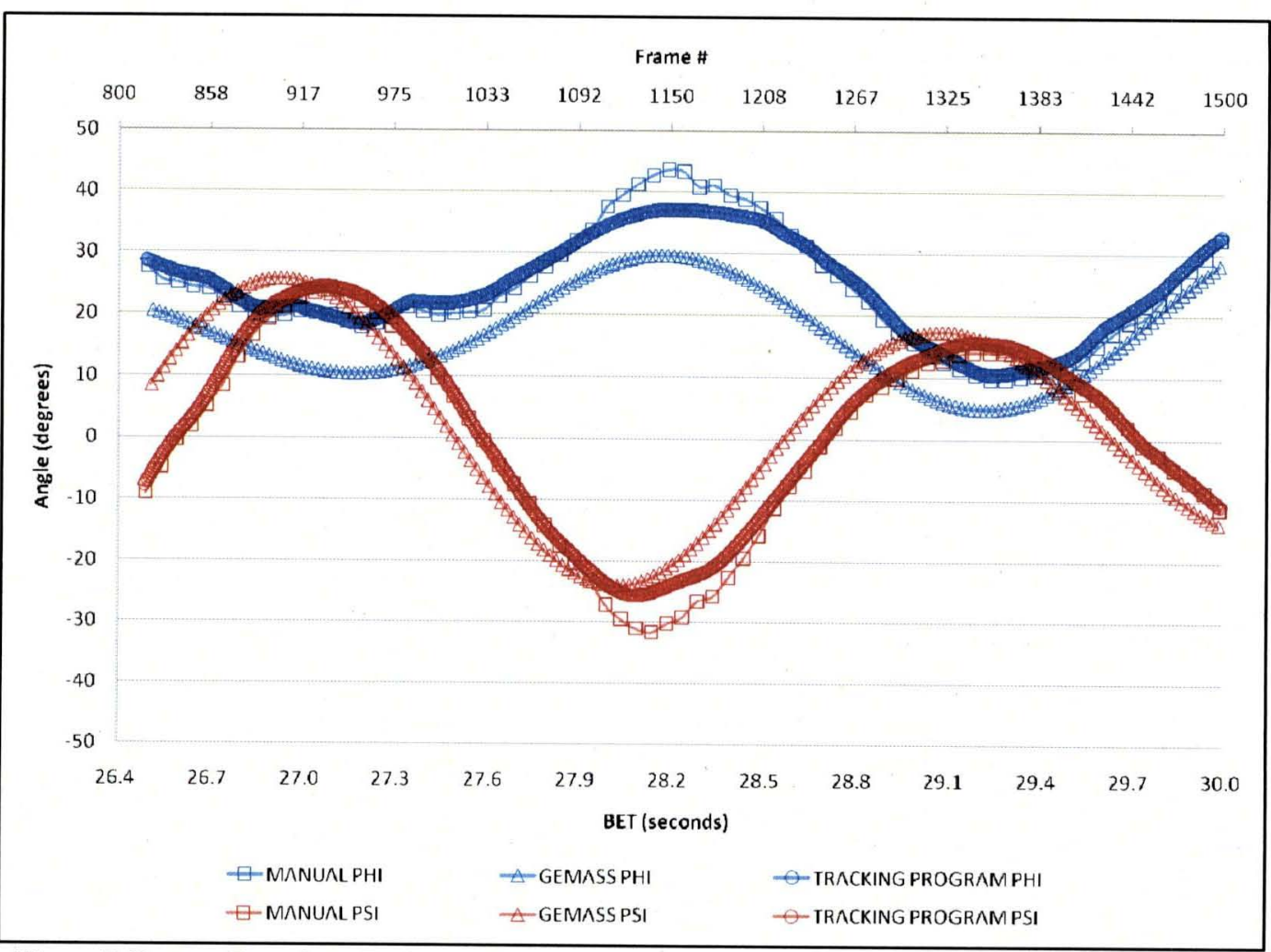

Figure 7. Drogue Parachute Body Axis Pitch Angle, Phi, and Yaw Angle, Psi, from CM Attach Point.

In general, the manual analysis method and the tracking program method agree very well both in amplitude and phase for both the pitch and the yaw angles. There is evidence of the GEMASS analysis exhibiting lower amplitude in pitch and slight negative phase in yaw compared to the manual and tracking program analyses. A bias in both amplitude and phase of +7 degrees and 0.05 seconds in the pitch angle and -1 degrees and 0.12 seconds in the yaw angle was implemented to correct for this variation. These slight shifts in amplitude and phase do not have a significant impact on the drogue parachute damping as the legacy parachute damping model is not sensitive to biases of 10-15 degrees in the pitch and yaw angles. Figures 8-11 illustrate the drogue parachute movement in pitch and yaw without (Figures 8 and 10) and with (Figures 9 and 11) implementing the bias. 


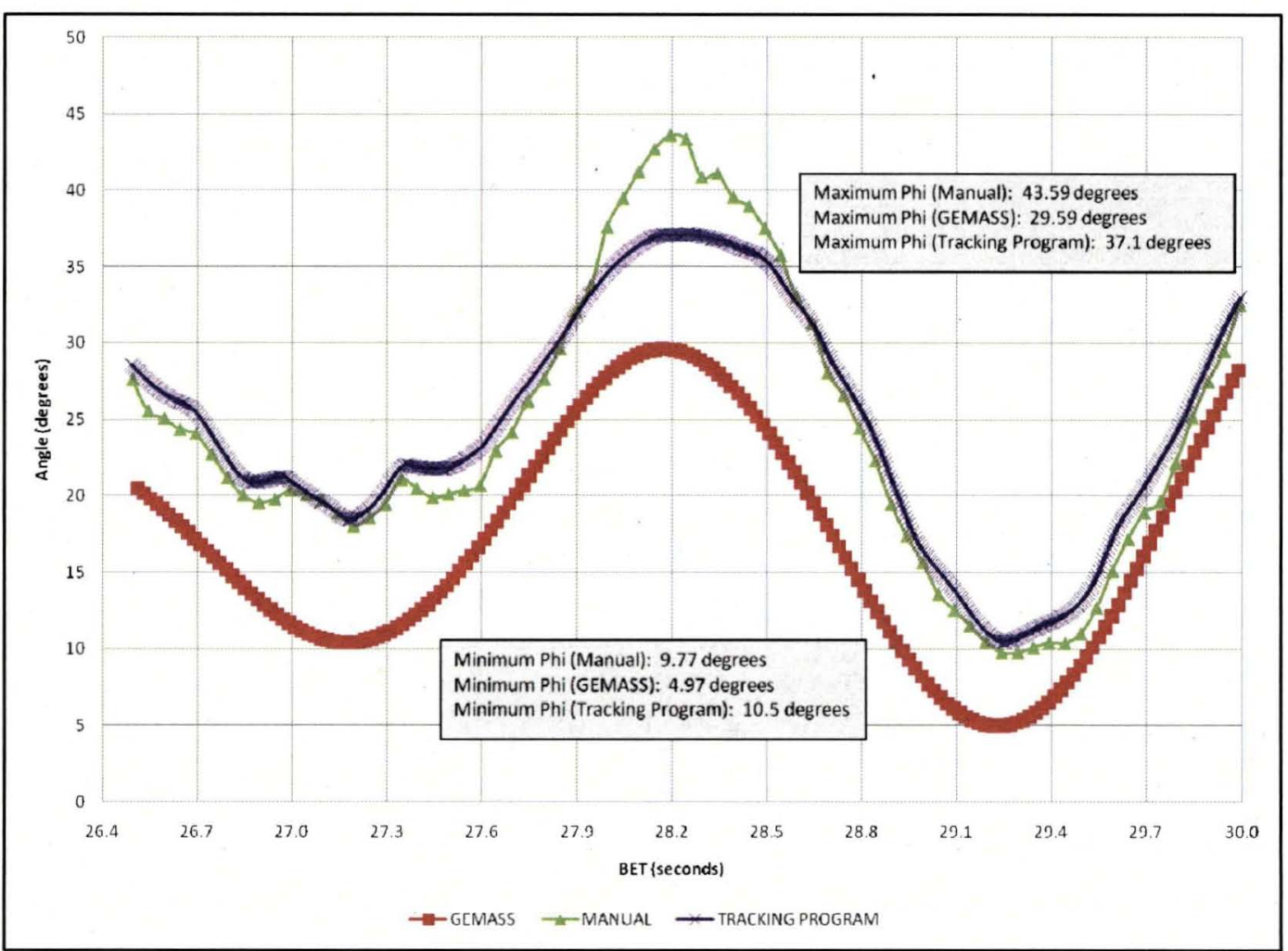

Figure 8. Drogue Parachute Body Axis Pitch Angle, Phi, from CM Attach Point.

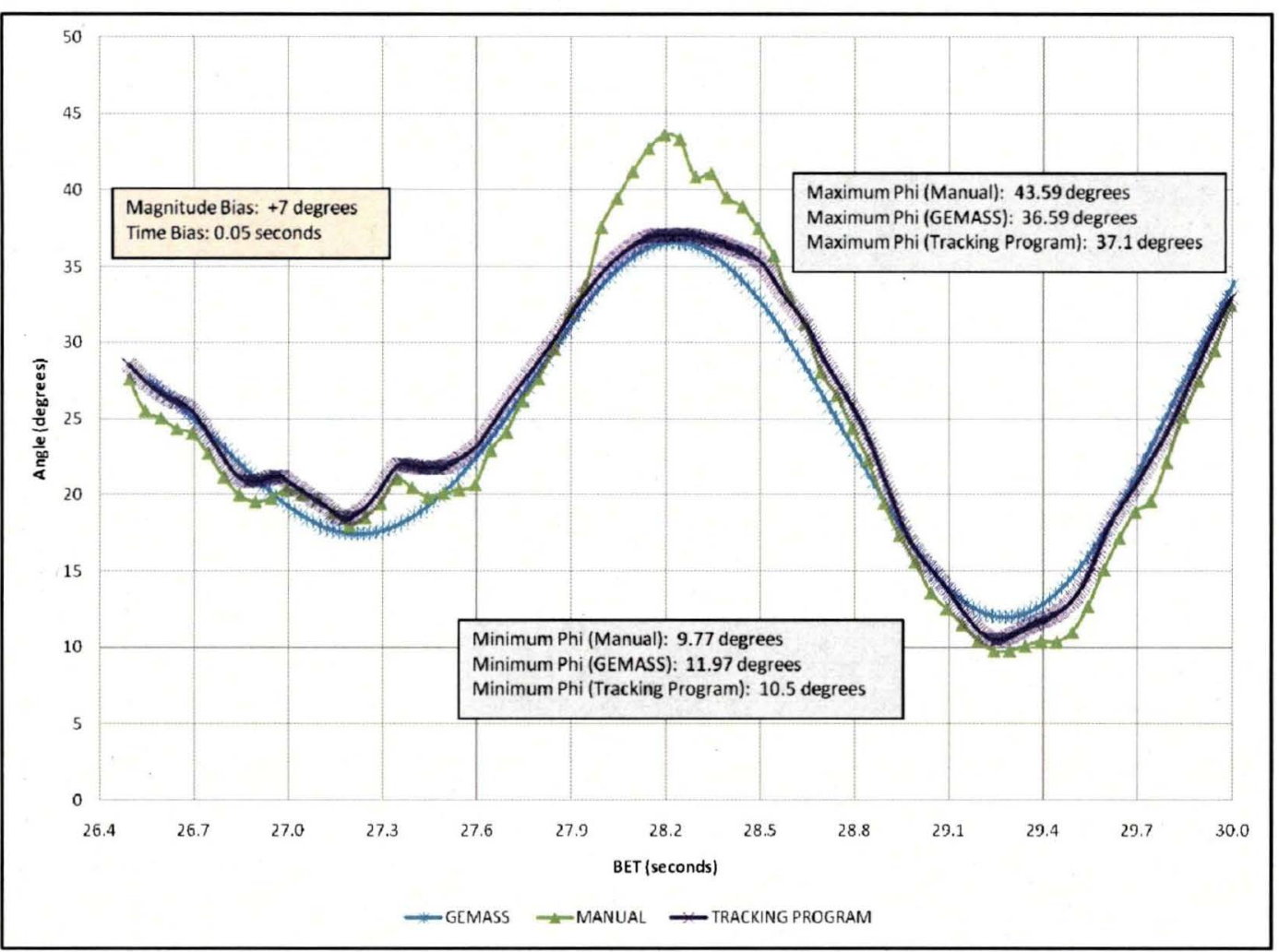

Figure 9. Drogue Parachute Body Axis Pitch Angle, Phi, from Attach Point Including GEMASS Data Bias. 


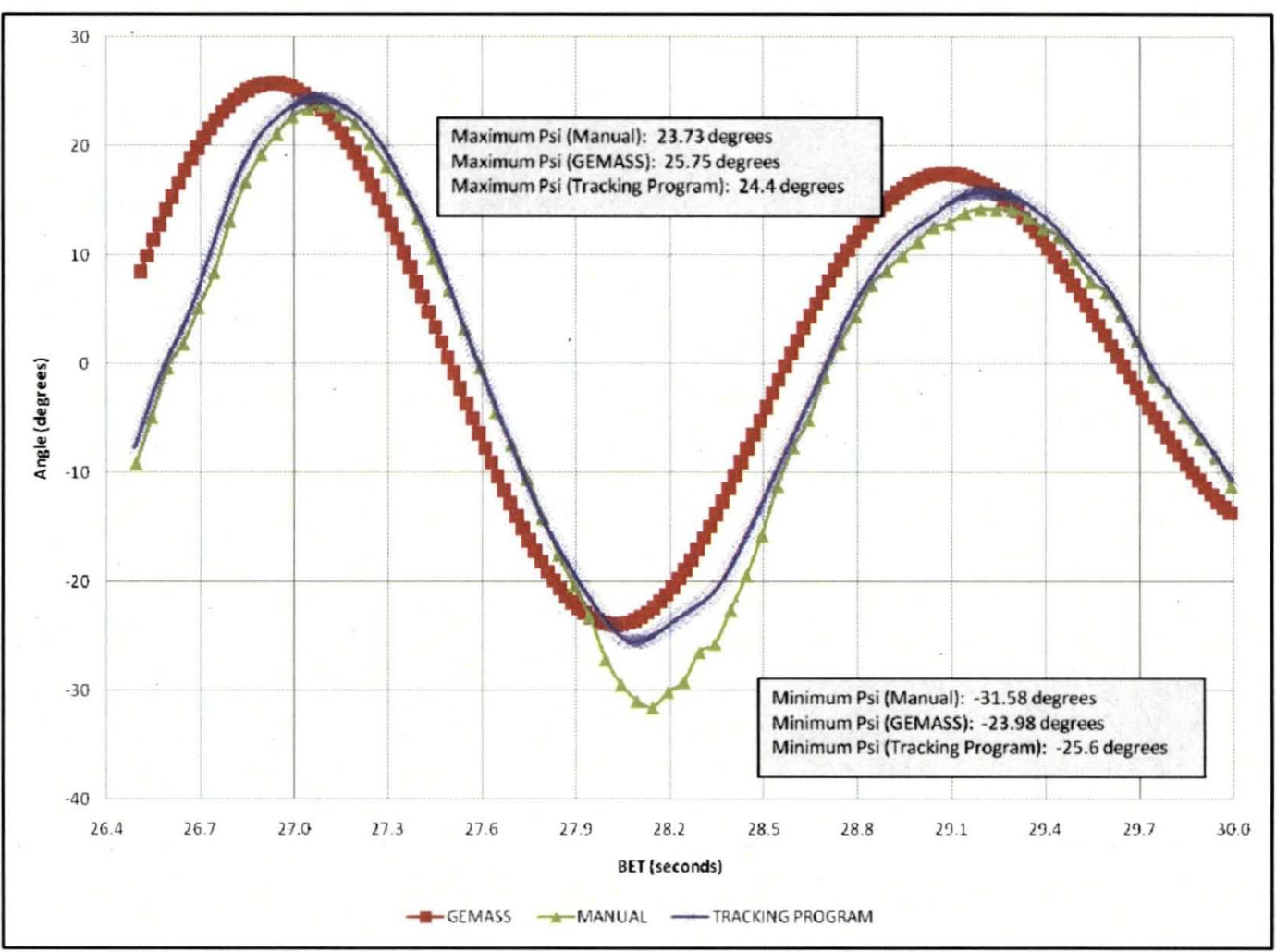

Figure 10. Drogue Parachute Body Axis Yaw Angle, Psi, from CM Attach Point.

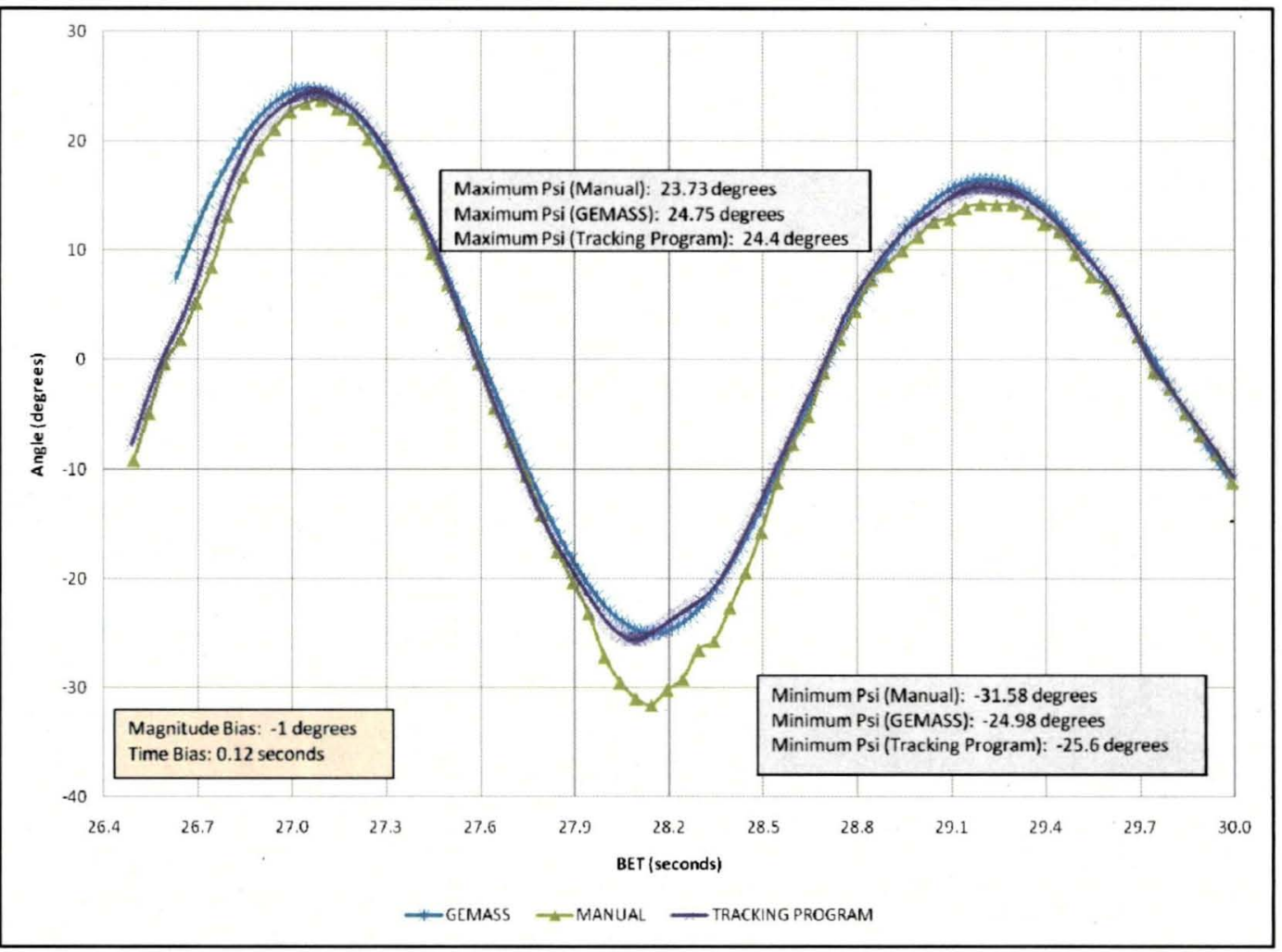

Figure 11. Drogue Parachute Body Axis Yaw Angle, Psi, from Attach Point Including GEMASS Data Bias.

Overall, the minimum and maximum pitch and yaw angles occur at approximately the same BET time near the beginning of the drogue parachute deployment for all three analysis methods. Prior to the implementation of the 
bias, the outliers in the minimum and maximum pitch and yaw angle values were those computed using the GEMASS analysis method. However, after implementing the bias, the outlier is the manual analysis method.

Several limitations were identified during the analysis:

1. Average tension vector: The average tension vector direction of the two drogue parachutes was used to determine the pitch and yaw angle measurements rather than determining the pitch and yaw angles for each individual parachute.

2. Wake behind CM: The wake behind the CM could have resulted in an angular bias to the flow, affecting the movement of the drogue parachutes.

3. Angle measurement location: The pitch and yaw angles were measured from the drogue attach point on the $\mathrm{CM}$ and not the camera attach point on the CM. It was assumed that the camera attach point was at the same $\mathrm{X}$ and $\mathrm{Z}$ location as the drogue parachute attach point, and the $\mathrm{Y}$ distance between the two points was significantly smaller than the riser line length therefore having little to no impact on the angle measurement.

4. Camera misalignment: There was a possibility of misalignment of the camera recording the drogue movement.

5. GEMASS simulation initial conditions: Slight modifications to the wind magnitudes (on the order of 5\%) in the GEMASS simulation were required to align the initial drogue parachute moments with the BET test data.

6. Camera lens distortion: Perhaps the most significant limitation was the inability of the manual measurement method to correct for camera lens distortion, which could be corrected for in the tracking program and was not a factor in the GEMASS simulation. During the time period from BET $=$ 13:00:27.900 seconds and BET $=13: 00: 28.500$ seconds, the parachutes were in the corner of the image, near the edge of the viewing field. As the parachutes approach the corner of the image, their appearance on the film becomes slightly distorted, making it difficult to measure the exact center location of the drogue parachute. The tracking program was able to correct for this distortion in the image, but the manual measurement method was not.

\section{B. 109-CD Vertical Spin Tunnel Analysis Results}

Figures 13-16 show the pitch rate and angle of attack comparisons for the test data and simulation for the 1- and 2drogue parachute cases. 


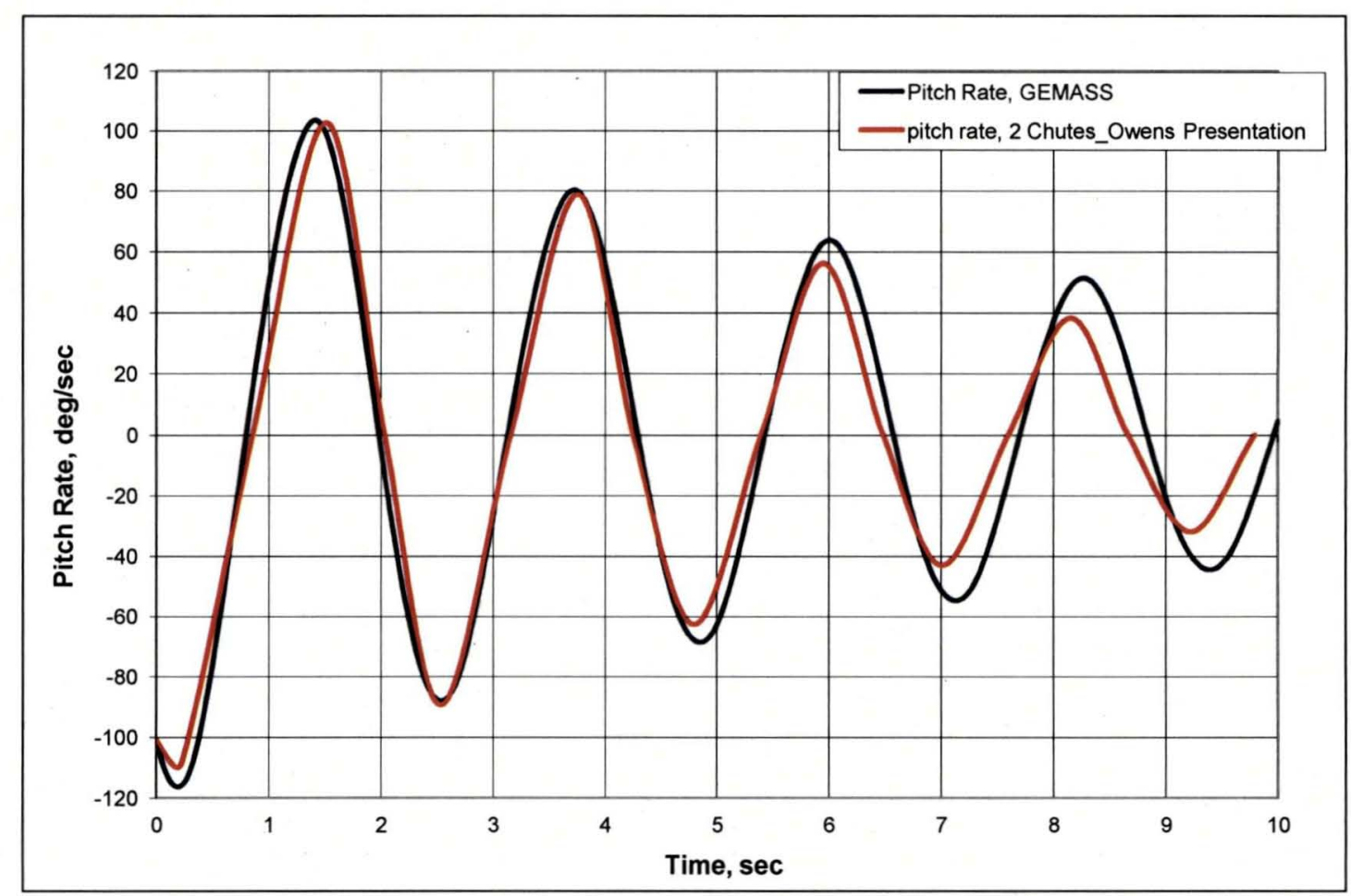

Figure 12. Comparison of Pitch Rates for 109-CD Two-chute Case.

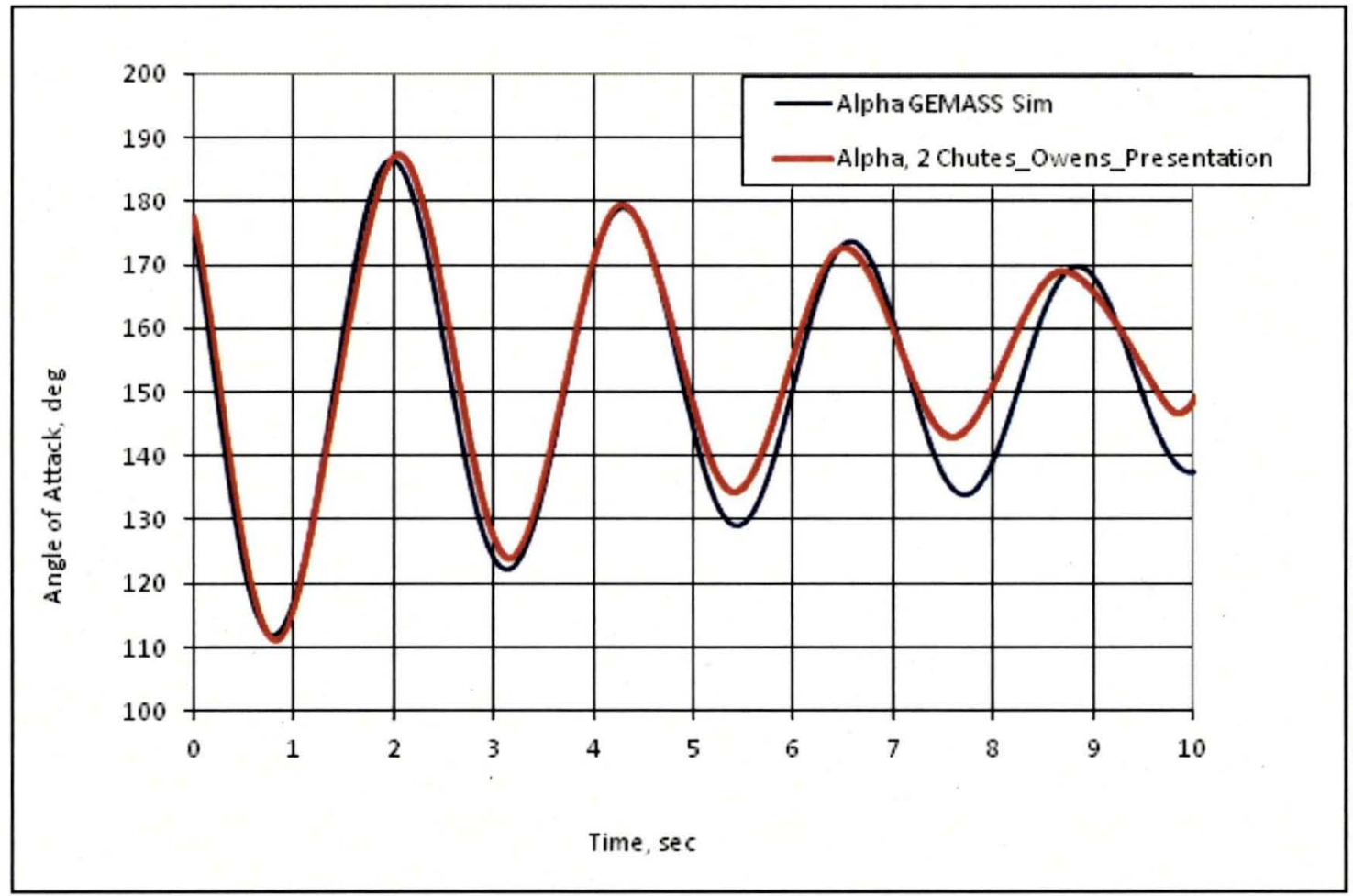

Figure 13. Comparison of Angles of Attack for 109-CD Two-chute Case. 


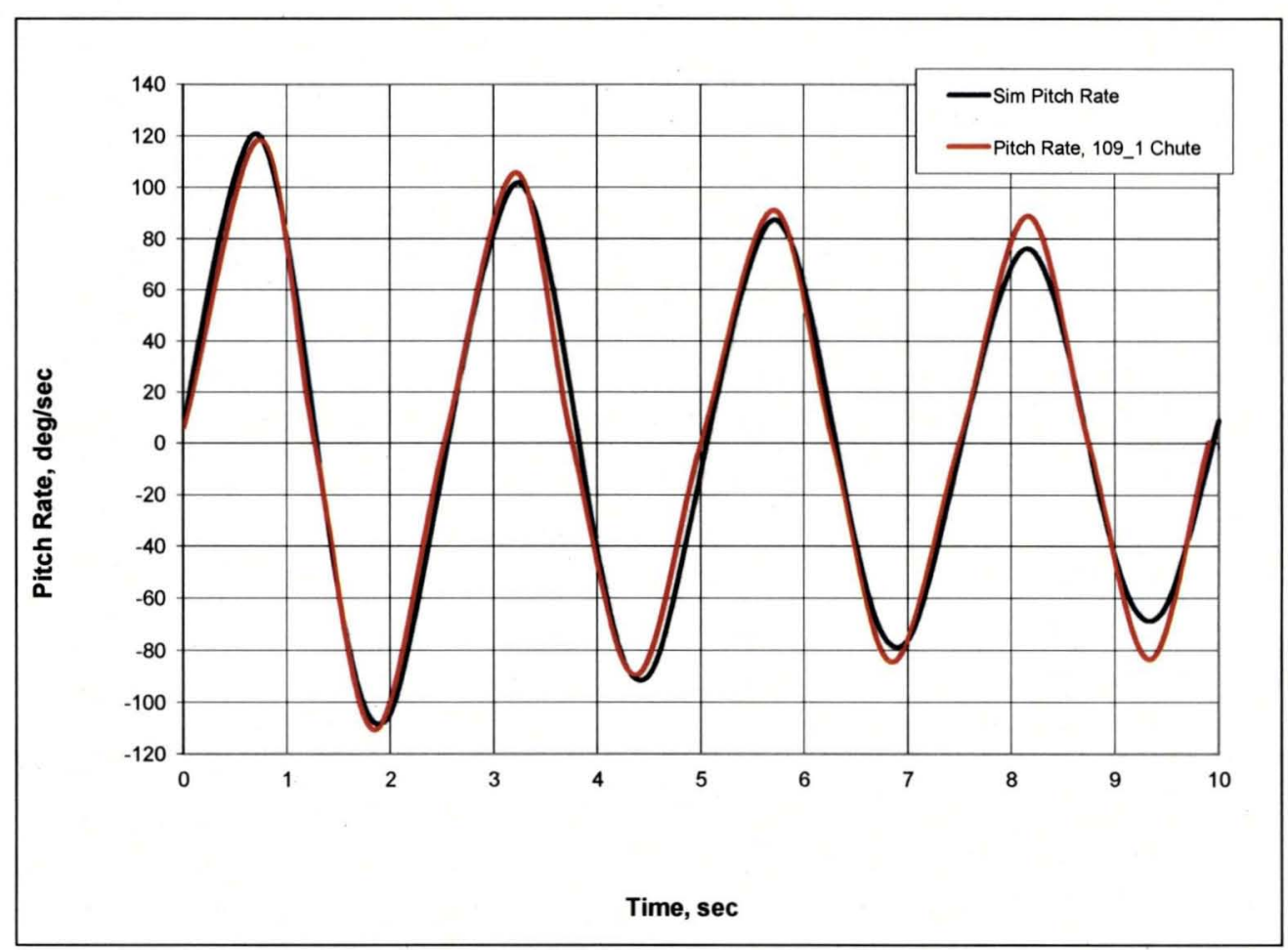

Figure 14. Comparison of Pitch Rates for 109-CD One-chute Case.

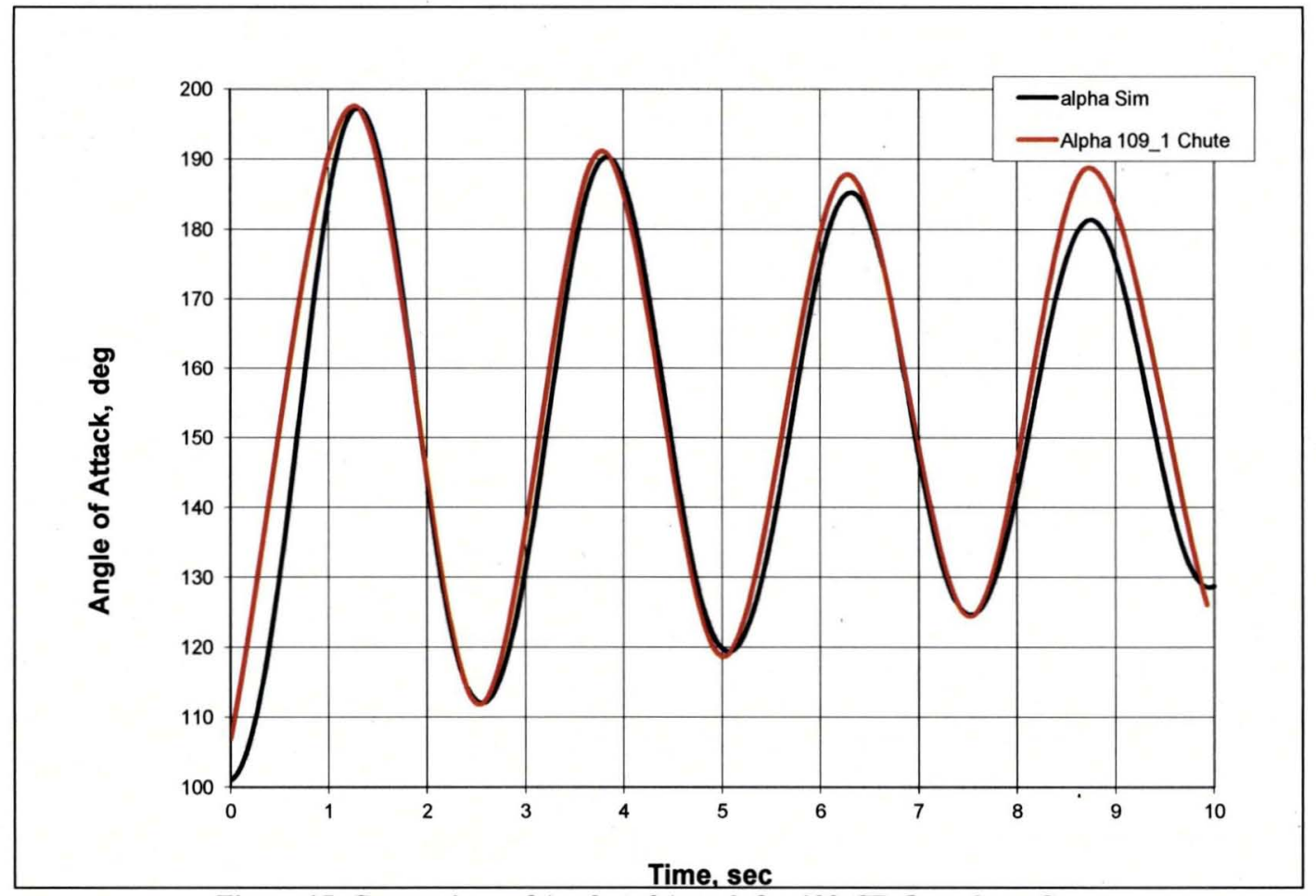

Figure 15. Comparison of Angles of Attack for 109-CD One-chute Case.

The two parachute case shows good agreement for the first two cycles but then the simulation is underdamped for the last two oscillations. Conversely the one parachute case shows good agreement for the first two cycles but the simulation is overdamped for the last two oscillations. Wind tunnel data has shown that the magnitude of the $\mathrm{Cm}_{\mathrm{q}}$ for the CM is dependent on the oscillation amplitude. The 109-CD test results suggest that the CM damping is more unstable for large amplitude oscillations as observed for the one parachute case and for the first two cycles in the 
two parachute case, but becomes less unstable at smaller oscillation amplitudes. Wind tunnel test data has shown that the CM typically has an unstable $\mathrm{Cm}_{\mathrm{q}}$ peak occurring over several degrees of alpha with stable $\mathrm{Cm}_{\mathrm{q}}$ values outside of this alpha range. The CM in the 109-CD test could be oscillating into more of the unstable $\mathrm{Cm}_{\mathrm{q}}$ region for the large oscillations and then experiencing less unstable $\mathrm{Cm}_{\mathrm{q}}$ values for the smaller amplitude oscillations.

Comparison of the simulation data and the 109-CD test results indicate the Apollo legacy drogue damping model provides a good approximation to the drogue damping.

\section{Concluding Remarks}

The manual measurement of the drogue parachute motion and the tracking program measurement of the drogue parachute motion agree very well in both the pitch and yaw angles, as shown in Figure 6. However, there is a variation in the magnitude between $B E T=13: 00: 27.900$ seconds and $B E T=13: 00: 28.500$ seconds that can be attributed to distortion near the edge of the viewing field. As described above, the lens distortion could not be corrected for in the manual measurements but could be corrected for in the tracking program measurements. Future comparisons between the GEMASS simulated data and the PA-1 flight data should utilize the tracking program analysis as opposed to the manual measurement analysis of the drogue parachute motion. The tracking program analysis of the PA-1 video is more accurate as it analyzed $100 \%$ of the frames when the drogue parachutes were in view as opposed to the manual measurement analysis of only $10 \%$ of the frames when the drogue parachutes were in view. However, the independent manual measurements of the motion of the drogue parachutes validate the tracking program analysis.

Additionally, although there is a bias in the GEMASS simulation data, the motion of the simulated data and the flight data are almost identical. Implementing a bias in the GEMASS simulation data better aligns the pitch and yaw angles and produces a more favorable comparison. These correlations between the GEMASS simulated data and the PA-1 flight data drogue parachute motion significantly contributes to building confidence in the legacy parachute damping model.

The high-fidelity parachute model remains the preferred tool for simulating the Orion MPCV parachute system, because of its ability to capture multi-body dynamics. However, it is clearly under predicting the damping produced by the drogue parachutes. Therefore, it was desirable to apply the Apollo legacy damping to the high-fidelity parachute model. This was achieved by modifying the drogue parachute force direction such that it is consistent with the Apollo legacy assumption of opposing the attach point velocity vector. This provides the moment arm hysteresis and thus the desired damping behavior. Figure 12 shows a comparison between the PA-1 BET Crew Module body rates under the drogue parachutes and reconstructions performed with the high-fidelity parachute model, showing how the addition of the Apollo legacy damping model provides a better match to the flight data. 


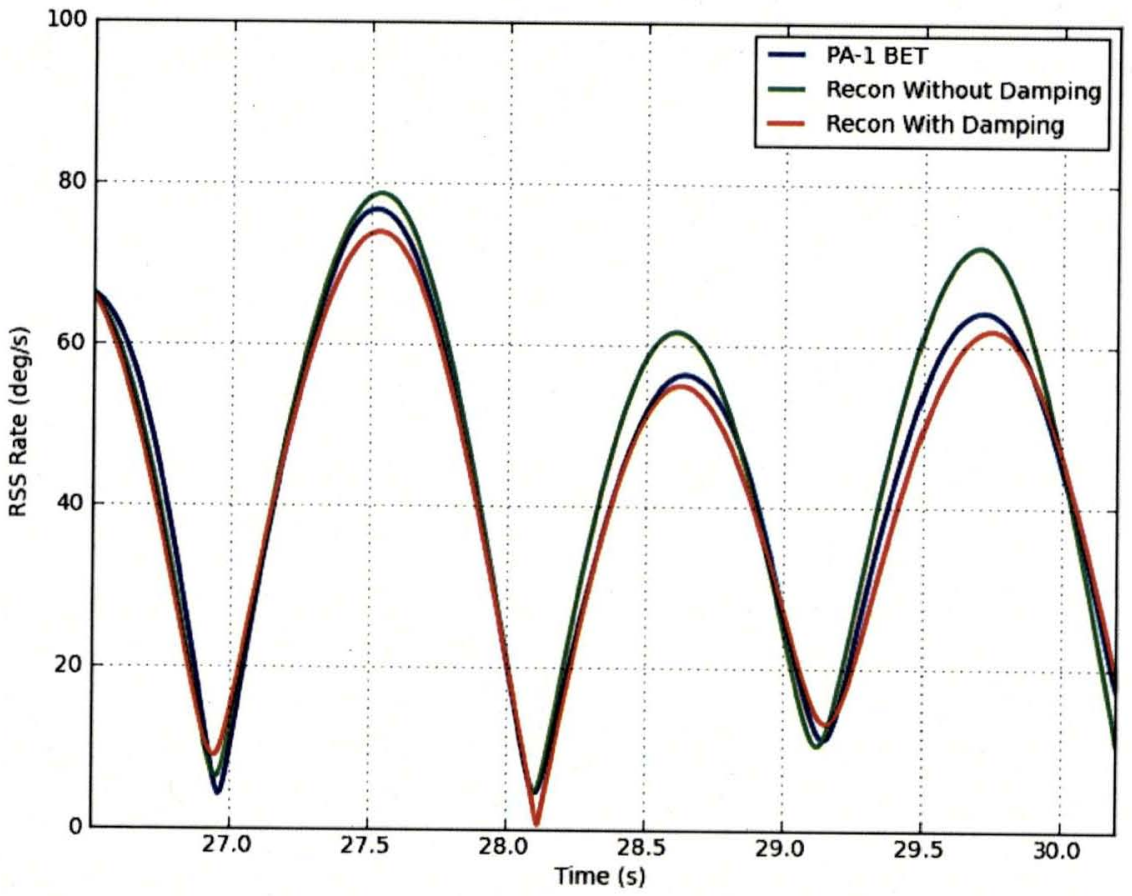

Figure 16: Comparison of High-Fidelity Parachute Model CM Body Rates With and Without Apollo Legacy Damping

Test 117-CD Part 2 is a forced oscillation test that will further validate the key assumptions of the legacy damping model using a $1 / 16^{\text {th }}$ scale model of the Orion CM. The test will be conducted in the NASA LaRC 20 -ft Vertical Spin Tunnel (VST) and is planned for early 2012. The test will utilize a six-component balance for the CM forces and moments and a force balance for the drogue riser line force vector. This test setup will provide data of the drogue line force vector with time correlated to the $\mathrm{CM}$ force and moment data in time. The angle of attack, angle of sideslip, number of drogues $(0,1$, and 2$)$, riser line length, drogue parachute diameter, and boundary layer trip method will be varied during the test. This test is sponsored by the NESC and is a continuation of test 117-CD Part 1 , in which the static force and moment, damping derivatives and drogue parachute line force magnitude were measured. ${ }^{5}$ 
$x+y$

Appendix A:

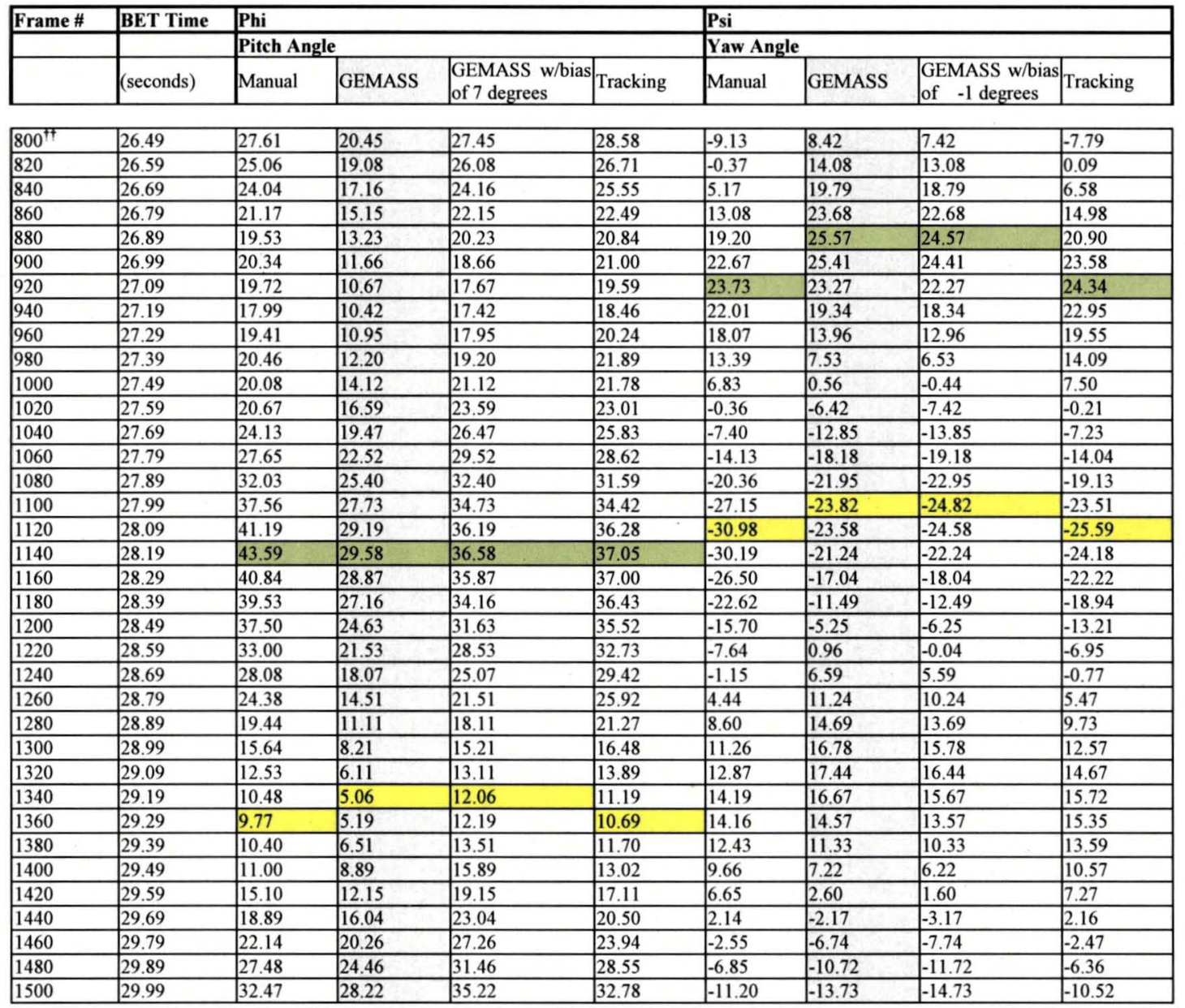

${ }^{7 \dagger}$ Note the GEMASS analysis begins at Frame \#804, corresponding to BET $=13: 00: 26.510$ seconds. 


\section{Acknowledgments}

K.M.C. Author would like to thank Rick Barton, David Bretz, Joe Gamble, Daniel Matz, Bruce Owens, and Bass Redd for their contributions and guidance during this analysis and for their technical review of this publication.

\section{References}

${ }^{1}$ Gamble, Joe D., Lockheed Martin Space Systems Company Technical Memo CEV-SA-11-013, "Equations for Equivalent Damping and Frequency from Drogue Chutes", 27 April, 2011.

${ }^{2}$ Schuster, David M., "Investigation of the Effect of Drogue Parachutes on Orion Crew Module Dynamics," NESC Initial Request TI-10-00678, Nov. 2010.

${ }^{3}$ Estes, Jay N., "Orion Pad Abort 1 Flight Test Overview," Media Briefing, Apr. 2010.

${ }^{4}$ Owens, D.B., Riddick, Matz, Fremaux, "IDAT Drogue Parachute Assessment in the NASA LaRC Vertical Spin Tunnel (VST) (Test 109-CD)", NASA LaRC presentation, Feb. 2010.

${ }_{5}^{5}$ Owens, D.B., and Aubuchon, V., "Determination of Drogue Riser Line Force Vector for the Orion Crew Module - 117-CD Part 2," CAP Aerosciences TIM, Sep. 2011. 